\title{
Filosofia, existência e finitude: Eugen Fink e a legitimidade de uma antropologia filosófica
}

\section{Philosophy, existence and finitude: Eugen Fink and the legitimation of a philosophical anthropology}

\section{Prof. Dr. José Fernandes Weber jweber@uel.br \\ Universidade Estadual de Londrina}

Tendo por referência a obra Fenômenos fundamentais da existência humana, de Eugen Fink, busca-se explicitar o projeto finkiano de legitimação de uma antropologia filosófica. A partir do modo como Husserl e Heidegger compreendem a especificidade de uma atitude filosófica fenomenológica, apresenta-se a recusa de Fink às críticas de Husserl e Heidegger ao projeto de elaboração de uma antropologia filosófica. Por fim, apresenta-se a compreensão finkiana de existência, vinculando-a à noção de finitude. Com isso, se esclarece, não a especificidade da antropologia filosófica de Fink, mas antes, seu esforço preliminar da sua legitimação filosófica.

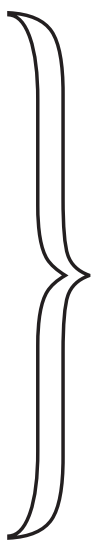

$\begin{array}{ll}\text { PALAVRAS-ChaVE } & \text { Eugen Fink. Antropologia Filo } \\ \text { Filosofia. Existência. Finitude. }\end{array}$

Having as reference Eugen Fink's work Fundamental phenomena of human existence, we try to make clear Fink's project of legitimation of a philosophical anthropology. From the way Husserl and Heidegger comprehend the specificity of a phenomenological philosophical attitude, we present Fink's refusal of Husserl's and Heidegger's critics of the project of elaboration of a philosophical anthropology. At the end, we present Fink's comprehension of existence, linking it with the notion of finitude. With this, we make clear not the specificity of Fink's philosophical anthropology but, his preliminary effort of its philosophical legitimation.

Idealism. Noema. Phenomenology.

Transcendental Philosophy. Metaphysics. 
Filosofia é menos um saber douto que um modo de existir. [...] Ela nada mais é que a relação mais tensa da existência consigo mesma, e nisso consiste a fonte do seu compreender e do seu interpretar (Eugen Fink).

Cada nova teoria filosófica expressa implicitamente, num nível mais fundamental aos problemas que pretende resolver por meio da elaboração conceitual, uma nova definição do que é filosofia. Assim, cada teoria filosófica, mesmo quando a isso não se propõe, apresenta, a seu modo, uma definição particular, dada em nome próprio, do que é filosofia, mas, ao mesmo tempo, também fornece indicações sobre o que é requerido e sobre o que deve ser evitado para a instauração de um autêntico ato de filosofar. Em linguagem fenomenológica: a atitude requerida ao filosofar. Daí ser possível afirmar que, para a fenomenologia, filosofia é uma questão de atitude!

Em A ideia da fenomenologia, à "atitude intelectual/espiritual natural”, Husserl contrapõe a fenomenologia, assim definida: "[...] uma ciência, uma conexão de disciplinas científicas; mas, ao mesmo tempo e acima de tudo, 'fenomenologia' designa um método e uma atitude intelectual; a atitude intelectual especificamente filosófica, o método especificamente filosófico" (HUSSERL, 1990, p. 46). A mútua implicação e dependência entre método e atitude fenomenológicos constitui um ethos próprio do fenomenólogo enquanto pesquisador, um modo de ser no qual vige a recusa, tanto da atitude intelectual/espiritual natural, o psicologismo da orientação natural, mas também do cientificismo. É na noção de Epoché que se expressa a conexão entre método e atitude ${ }^{1}$.

No § 32 de Ideias I, Husserl caracteriza a Epoché como uma operação radical de restrição, uma "exclusão fenomenológica" (HUSSERL, 2006, p. 84), que consiste em interditar a aceitação das evidências contidas nas teses da orientação natural, mas também nas proposições das ciências: "Não me aproprio de uma única proposição sequer delas" (Idem, p. 81), diz ele. Tal atitude expressa uma dupla exclusão: "Colocamos fora de ação a tese geral inerente à essência da orientação natural" (Ibidem); e "Tiro, pois, de circuito todas

1 A fim de padronizar o uso do termo com a tradução brasileira feita por Márcio Suzuki, optou-se por manter a expressão grega transliterada Epoché ao invés de traduzi-la por redução. E isso se deve, não apenas a um preciosismo terminológico, e sim, a razões conceituais, pois o próprio Husserl distingue Epoché de redução: a primeira, seria a atitude de recusa do mundo em orientação natural; a segunda, a atitude de adentrar o campo transcendental, apenas avistado como possibilidade na Epoché. A respeito dessa distinção, conferir: HUSSERL (2002; 1990, pp. 67-74; 2006, pp. 81-82; pp. 131-142). 
as ciências que se referem a esse mundo natural" (Ibidem) ${ }^{2}$. Disso surge uma inevitável questão, que o próprio Husserl (Idem, p. 86) se põe: “O que pode, pois, restar, se o mundo inteiro é posto fora de circuito, incluindo nós mesmos com todo nosso cogitare?". Resta, responde Husserl, a “[...] evidência de que a consciência tem em si mesma um ser próprio, o qual não é atingido em sua essência própria absoluta pela exclusão fenomenológica" (Idem, p. 84). Portanto, a Epoché cria as condições para a aparição da evidência do modo imanente de ser da consciência.

A radicalização destas teses é formulada de modo emblemático no $§ 49$ de Ideias I, por meio da formulação da "hipótese da aniquilação do mundo [Weltvernichtung]".

[...] o ser da consciência, todo fluxo de vivido em geral, seria necessariamente modificado por uma aniquilação do mundo de coisas, mas permaneceria intocado em sua própria existência. [...] nenhum ser real, nenhum ser que se exiba e ateste por aparições à consciência, é necessário para o ser da própria consciência (no sentido mais amplo do fluxo do vivido). [...] Um verdadeiro abismo de sentido se abre entre consciência e realidade. Aqui, um ser que se perfila, que não se dá de modo absoluto, mas meramente contingente e relativo; lá, um ser necessário e absoluto, que não pode por princípio ser dado mediante perfil e aparição. [...] está claro, portanto, que a consciência, considerada em sua 'pureza', tem de valer como uma conexão de ser fechada por si, como uma conexão do ser absoluto, no qual nada pode penetrar e do qual nada pode escapulir; que não tem nenhum lado de fora espaço-temporal e não pode estar em nenhum nexo espaço-temporal, que não pode sofrer causalidade de coisa nenhuma, nem exercer causalidade sobre coisa nenhuma (HUSSERL, 2006, p. 115-116).

Importa perceber nesta passagem, que a hipótese da aniquilação do mundo não é um passatempo de um cético, levado a cabo por uma lógica imaginativa, nos moldes da primeira das Meditações de Descartes. Diz Husserl (Idem, p. 81),

2 A este respeito, conferir o esclarecedor $\S 15$ da Meditações cartesianas, intitulado Reflexão natural e transcendental (HUSSERL, 2010, pp. 81-84). 
"[...] não nego este 'mundo', como se eu fosse um sofista, não duvido de sua existência, como se fosse cético, mas efetuo a Epoché 'fenomenológica', que me impede totalmente de fazer qualquer juizo sobre existência espaço-temporal". Trata-se, portanto, de reter "[...] somente o fenômeno de 'pôr entre parênteses' ou "tirar de circuito"' (Idem, p. 80) e de pôr fora de ação, tanto os juízos quanto o assentimento aos juízos. Numa conferência nos famosos Colóquios de Royaumont, em abril de 1957, intitulada Os conceitos operatórios na fenomenologia de Husserl, Eugen Fink (1994, p. 63) assinala que "pelo método da 'redução', Husserl abre o campo da subjetividade absoluta que, nos seus processos vitais de natureza intencional, 'edifica' toda objetividade mundana"s.

Portanto, a denominação feita por Husserl (2010, p. 15) no parágrafo de abertura das Conferências de Paris, segundo a qual a fenomenologia seria “[...] um novo Cartesianismo, um Cartesianismo do século XX", não é mera frase de efeito para agradar a plateia parisiense. Será, ao juízo de Husserl, um cartesianismo consequente com a enorme intuição de Descartes, agora, porém, livre da pressuposição do ideal de ciência que acabou se esgueirando pela porta dos fundos, operando como estrutura oculta do edifício cartesiano do saber ${ }^{4}$. Além disso, a redução fenomenológica radicalizará o gesto cartesiano de suspensão da crença natural no mundo. Se Descartes realizou a Epoché, faltou-lhe, contudo, efetivar a redução fenomenológica.

Jan Patocka, num breve, mas esclarecedor texto sobre Heidegger, sustenta que

Husserl busca, com a ajuda da redução fenomenológica, mostrar que, num verdadeiro sentido filosófico, os fenômenos são relativos à subjetividade transcendental, por meio da qual se alcança a suspensão da crença no mundo, a suspensão da 'tese geral da orientação natural'. O ponto de vista de Heidegger me parece ser a única resposta radical ao pensamento altamente especulativo da redução. (PATOCKA, 1999, p. 398).

3 Embora Husserl distinga Epoché de redução, Fink reinterpreta o conceito de redução e concebe a Epoché como um momento da redução. Assim, a redução prepara o abandono da orientação natural, com o que a própria referência à Epoché se torna dispensável. A esse respeito, conferir GIUBILATO, 2017, pp. 73-80.

4 Não será aqui abordado o problema que consiste em saber se a Husserl também não preside um ideal de ciência e de conhecimento orientador, inclusive, do reconhecimento da necessidade da instauração da Epoché. 
Por essa razão, segundo Patocka, o sentido da ontologia fundamental de Heidegger consiste em mostrar fenomenologicamente que "[...] a fenomenologia transcendental, do modo como Husserl a compreendeu, é impossível" (Ibidem). E isso pelo simples fato de que “a 'crença no mundo' e a tese geral não são nenhuma crença ou tese que possam ser suspendidas intelectualmente" (Ibidem), pois, tanto a crença quanto a orientação natural se dão, no contexto da filosofia de Heidegger, a partir do fenômeno da facticidade do Dasein, e não, como queria Husserl, da estrutura intencional da consciência. Vê-se, portanto, que a crítica de Heidegger a Husserl mostra-se como uma recusa da noção husserliana de Epoché. Se a atitude fenomenológica requerida por Husserl instituía-se em consonância com a Epoché, a crítica heideggeriana desta noção terá efeitos significativos sobre a compreensão do que seja a atitude própria ao filosofar, donde surgirá uma nova compreensão de atitude e da própria filosofia: apreender o sentido de ser do Dasein como ser-no-mundo. No deslocamento operado pela noção heideggeriana de facticidade, manifesta-se o reconhecimento de que, excluída tal dimensão, diz Patocka (1999, p. 399), “[...] nada somos, não existimos”. Dar abertura à facticidade em que é manifesta a finitude como modo de ser do $D a$ sein, eis a nova atitude filosófica. Nos últimos anos, Heidegger concebeu tal atitude como coincidente com um pensar meditativo, um abrir-se à aparição do mundo, um modo de estar à espreita, à espera. Pensar meditativo, pensamento poético, intimidade, proximidade, simplicidade, abertura-clareira-iluminação, silêncio, quadratura (céu, terra, mortais, imortais) todas elas noções do "último Heidegger", antes de serem imagens, metáforas, figuras conceituais ou noções de pensamento, são disposições, "tonalidades afetivas fundamentais" (Grundstimmungen), atitudes de quem pensa originariamente, nas quais já não opera a distinção formal entre o teórico e o prático, às quais também são impostas restrições, interdições, que também exigem preparação, enfim, exercício, as únicas que possibilitariam acesso a um pensar que não seria mais representacional.

Portanto, essas distintas compreensões de atitude exprimem a compreensão da filosofia como uma atitude que exige zelo e constância, expressa como exercício, sempre novamente reposto, iniciado a cada momento, e que cria um modo de vida, o que autorizaria a concluir que a fenomenologia retoma ao seu modo o antiquíssimo problema da filosofia como exercício e cuidado de si, embora em outra chave interpretativa. 


\section{A antropologia filosófica de Fink: à sombra de Husserl e Heidegger?}

Eugen Fink, no semestre de verão de 1955, ministrou um curso, apenas publicado postumamente em 1979, sobre Os Fenômenos fundamentais da existência humana ${ }^{5}$. Nele, Fink se mostra um fenomenólogo sui generis: nem meramente husserliano, tampouco heideggeriano ${ }^{6}$. A própria concepção de uma antropologia filosófica, tanto no sentido geral da disciplina, quanto no molde proposto por Fink, é incompatível com as orientações fenomenológicas, tanto de Husserl quanto de Heidegger.

Embora, num plano mais restrito, particularmente nos parágrafos 5 e 6 dos Fenômenos fundamentais, Fink estabeleça um diálogo apropriativo das noções heideggerianas do humano como "ser no mundo", do "ser do ente "em cada caso meu" e do fenômeno da autenticidade/inautenticidade, ainda assim, é possível afirmar que a própria proposição de uma antropologia filosófica por parte de Fink é incompatível com o pensamento heideggeriano, pois, de acordo com San Martín (2006, p. 117): "[...] o que Heidegger acentua com clareza é a impossibilidade de uma antropologia filosófica enquanto ontologia regional, porque o homem não é um ente como os outros entes, pois nele se dá a compreensão do ser".

Bem conhecidas são as críticas de Heidegger à tentativa de compatibilização entre filosofia e antropologia. A antropologia, na medida em que opera no plano mais baixo de uma compreensão metafísica de mundo, esqueceria que a tarefa de pensar a essência do homem não repousa no homem ele próprio, e sim, surge no reconhecimento da dependência do homem para com a essência do ser ${ }^{7}$, como é possível ler na Carta sobre o humanismo. Portanto, a verdade do homem deve ser "[...] pensada a partir da questão da verdade do ser" (HEIDEGGER, 1973, p. 349). Aí também é possível ler:

[...] resta, enfim, perguntar se a essência do homem como tal, originalmente [...] realmente se funda na dimensão de sua animalitas. Estamos nós no caminho certo para a essência do homem, quando distinguimos o homem e enquanto o distinguimos, como ser vivo entre

5 Doravante, Fenômenos fundamentais.

6 Fink foi assessor de Husserl na década de 30, mas também manteve uma proximidade com Heidegger bastante marcante para seu pensamento, chegando a participar de alguns dos seus cursos, e teve os dois como avaliadores da sua tese de doutorado, Vergegenwärtigung und Bild (Presentificação e imagem).

7 A este respeito, conferir: SAN MARTÍN, 2006, p. 117; RUGGENINI, 2006, p. 143-148. 
outros, da planta, do animal e de Deus? Pode-se proceder assim, pode-se situar, desta maneira, o homem, em meio ao ente, como um ente entre outros. Com isso se poderá afirmar, constantemente, coisas acertadas sobre o homem. [...] Mas com isso a essência do homem é minimizada e não é pensada em sua origem. [...] A Metafísica pensa o homem a partir da animalitas; ela não pensa em direção de sua humanitas. (Idem, p. 352).

A antropologia, enquanto disciplina ôntica, pensa e estuda o ente homo na sua determinação enquanto animalitas, e opera, portanto, num plano existencial. Já a filosofia, que é essencialmente ontologia, pensa e estuda o ente homo enquanto ente, ou seja, no seu ser, sem considerar suas possíveis determinações e opera num plano existenciário. Assim, a antropologia, no seu sentido convencional, mas também a antropologia filosófica - essa tentativa tipicamente alemã do início do século XX, que busca compor o conhecimento sobre o homem a partir de um misto composto por filosofia e ciências particulares (na linguagem da fenomenologia: ciências fácticas) - padecem de um equívoco característico do pensamento ocidental: por operar no âmbito de um suposto saber prévio sobre o homem, não reconhecem o vínculo inevitável entre a essência do homem e a verdade do ser. Isso faz Heidegger (Idem, p. 353) arrematar:

Causa-nos a máxima dificuldade [...] pensar o ser vivo, porque, por um lado, de certo modo, possui conosco o parentesco mais próximo, estando, contudo, por outro lado, ao mesmo tempo, separado por um abismo da nossa essência ec-sistente. [...] em comparação pode até parecer-nos que a essência do divino nos é mais próxima, [...] próxima, quero dizer, numa distância essencial, que, enquanto distância, contudo, é mais familiar para nossa essência ec-sistente que o abissal parentesco corporal com o animal, quase inesgotável para o nosso pensamento.

Da parte de Fink, a incompatibilidade com a posição heideggeriana a respeito da plausibilidade de uma antropologia filosófica, reside em sua crítica à compreensão heideggeriana do humano, Dasein, mais particularmente, nesta compreensão, ao modo como Heidegger vincula Dasein e mundo. No aspecto geral da influência de Heidegger no pensamento de Fink, é preciso reconhecer, como nota Ruggenini (2006, p. 143), que 
o tema heideggeriano do ser-no-mundo da existência põe Fink no caminho certo, mesmo que tenha que também ser reconhecido que a pergunta pelo mundo em Ser e Tempo, quanto ao seu fundamento e à sua execução, ainda seja muito fortemente dependente da fenomenologia.

Se, portanto, o deslocamento da explicação do humano em direção à facticidade e à dimensão mundana do Dasein representa uma radicalização compreensiva significativa na compreensão do humano, por outro lado, de acordo com Fink, em Heidegger, o reconhecimento do caráter "mundano" da existência não altera o fato de que o mundo, constitutivo do modo de ser do Dasein que é ser-no-mundo (estrutura existencial), ainda continua a ser concebido a partir do domínio da subjetividade ${ }^{8}$. Portanto, a crítica de Fink a Heidegger reside na compreensão segundo a qual "a relação ao mundo tem seu fundamento, não no ser humano, e sim, no mundo" (Idem, p. 144). Isso pode ser visto no parágrafo de fechamento dos Fenômenos fundamentais, em que a expressão adequada do vínculo entre homem e mundo é apresentada da seguinte maneira:

O mundo não é um resultado antropológico, nenhuma estrutura existencial da existência humana. Antes, sim, o homem é o único dentre todos os entes que se mostra ao aparecer, que não sabe meramente do mundo, senão que sabe dele enquanto quintessência e fundamento originário de todas as coisas. (FINK, 1979, p. 450).

Por sua vez, o sentido mais elementar da incompatibilidade da antropologia filosófica de Fink com os ensinamentos de Husserl pode ser vista, por contraposição, com aquilo que o próprio Husserl declarava sobre a antropologia. Num cartão postal de 22 de fevereiro de 1937 destinado a Karl Löwith, Husserl exorta:

8 Parece-nos que nesta crítica opera uma objeção similar, embora por razões distintas e com propósitos outros, daquela feita por Husserl a Heidegger, encontradas nas suas anotações às margens do seu exemplar de Ser e Tempo. Numa delas é possível ler: "Heidegger transpõe ou transverte para o antropológico a clarificação constitutivo-fenomenológica de todas as regiões do ente e do universal, da região total do mundo; toda a problemática é transferência, ao ego corresponde a existência etc. Aqui tudo se torna profundamente obscuro e, em termos filosóficos, perde seu valor". (HUSSERL apud ARLT, 2008, p. 58). Ou seja, em Ser e Tempo, Heidegger teria decaído em uma orientação antropológica. Já para Fink, Ser e Tempo seria uma obra "excessivamente fenomenológica" (entenda-se: acrítica com relação ao preconceito antropológico husserliano e dele dependente), e subjetivista. 
Oxalá o senhor não faça parte dos "precocemente consumados", chegados a uma posição pronta, de modo que o senhor ainda tenha a liberdade interior para "por entre parênteses" a sua antropologia e compreender com base em minha nova exposição, mais amadurecida, por que eu considero toda antropologia como uma posição ingênua, em termos filosóficos, e por que eu reconheço o método da redução fenomenológica como o único filosófico, como o único que alcança um conhecimento do Ser ou uma auto-reflexão universal em real concreção. Talvez o senhor entenda então que Scheler, Heidegger - e todos os ex "discípulos" - não entenderam o verdadeiro e profundo sentido da fenomenologia - da transcendental como a única possível - e quanta coisa depende disso (HUSSERL apud LÖWITH, 1984, pp. 236-237).

Husserl, num tom paternal, aconselha a Löwith operar a redução, pois sem ela não há fenomenologia. Percebendo a heresia ${ }^{9}$, em que os mais brilhantes discípulos se tornam "ex discípulos" (Scheler e Heidegger), no conselho de Husserl soa um clamor: que não se permita à fenomenologia, que é a filosofia em sentido estrito, recair numa posição ingênua, ou seja, tornar-se antropologia. A fenomenologia ou é transcendental ou nada, torna-se antropologia, o que, filosoficamente considerado, dá na mesma. Segundo San Martín,

para Husserl a antropologia ou é uma ontologia regional ou uma ciência factual de um ente mundano. Por essa razão, o saber da subjetividade transcendental, que, enquanto transcendental não está mais no mundo, não pode mais ser apresentada em uma antropologia. (2006, p. 117).

9 A respeito da intrínseca característica herética da fenomenologia enquanto um movimento filosófico, Paul Ricoeur (2009, pp. 08-09) afirma: "Ainda que a fenomenologia no sentido lato seja a soma da obra husserliana e das heresias que nasceram com Husserl, é também a soma das variações do próprio Husserl e, de modo particular, a soma das descrições propriamente fenomenológicas e das interpretações filosóficas pelas quais reflete e sistematiza o método". Destaque seja dado à identificação de uma característica herética nos discípulos de Husserl, o que também poderia valer, não apenas para identificar um desvio do mestre, embora Husserl assim o veja, mas também para expressar uma fidelidade aos próprios pressupostos, senão do método, ao menos, da atitude. Ressalvado, é claro, o fato de que, para Husserl, a atitude fenomenológica é instaurada na sua radicalidade pelo método da Epoché e da redução. Não há, portanto, para Husserl, atitude fenomenológica autêntica sem Epoché e redução. 
A oposição de Fink à denúncia husserliana de uma suposta incoerência fenomenológica inerente à proposição de uma antropologia filosófica, expressa-se na recusa em renunciar à realidade da nossa existência para explicá-la. No primeiro parágrafo de Fenômenos fundamentais, ele afirma:

A essência da existência humana jamais é apreensível caso se queira abstrair da realidade. A realidade da nossa existência é o pressuposto de todas as nossas distinções entre essência e factum. Não podemos especular sobre nós mesmos suspensos no espaço vazio; temos de ser nós mesmos enquanto especuladores, e esse pressuposto é irrevogável. [...] Se perguntamos, então, pelas estruturas essenciais do homem, não nos guia, nem o olhar a uma ipseidade que se sustenta em toda a mudança histórica, tampouco a 'intuição da essência' que prescinde do fáctico. Pelo contrário, devemos tentar conservar todos os enunciados sobre os 'fenômenos fundamentais' de nossa existência [Existenz] numa interpretação da nossa existência atual. (FINK, 1979, p. 16)

Embora por razões distintas daquelas que presidem o repúdio, por parte de Heidegger, de uma antropologia filosófica, também a Husserl a formulação de uma antropologia filosófica parece uma tarefa contraditória, pelo simples fato de que na sua elaboração, os vividos a serem considerados não são os vividos intencionais da consciência, do eu puro, transcendentalmente considerados ${ }^{10}$.

10 Para uma interpretação radicalmente divergente, conferir San Martín (2013, 2015a, 2015b, 2017). O autor concebe a fenomenologia husserliana como antropologia filosófica, e define sua posição nos seguintes termos: "[...] a filosofia de Husserl apresentava-se, a meu ver, como o único marco convincente para formular uma autêntica antropologia filosófica, mas não deixava indiferente à própria fenomenologia husserliana, até extrair o mais íntimo dela, que não era, nada mais do que a sua clara vocação antropológica, que marca o seu destino de ser uma antropologia filosófica, isto é, como primeira filosofia". (SAN MARTÍN, 2015 , p. 27). A possibilidade de se admitir a aproximação da "primeira filosofia" de Husserl - entenda-se, transcendental -, da antropologia, tendo em vista a amplitude dos seus escritos e a clara diferença entre a obra publicada e os manuscritos não publicados, mas também, a incorporação crescente às suas reflexões, em seus últimos anos, dos temas da intersubjetividade (Intersubjektivität), do corpo (Körper/Leib) e do mundo da vida (Lebenswelt), o que possibilitaria a aproximação entre antropologia filosófica e a fenomenologia husserliana, não deveria, contudo, obscurecer a percepção para o fato de que a aproximação temática à antropologia filosófica não torna a obra de Husserl uma antropologia filosófica. Seria o caso de averiguar se as modificações da fenomenologia de Husserl são amplas o suficiente para alterar sua noção de transcendental, pois disso depende todo o argumento de San Martín. Para o que nos interessa basta dizer que, nas obras publicadas por Husserl, as únicas aqui consideradas em nossa argumentação, Husserl é enfático nas suas críticas à antropologia. 
Portanto, isso que Fink chama de "estruturas essenciais do homem", ou "fenômenos fundamentais da existência humana", ocupam uma posição intermediária entre o domínio da "imaterialidade", seja o eu puro (Husserl) ou o ser (Heidegger), e a mera coisa. A partir de sua compreensão dos "fenômenos fundamentais da existência humana", Fink recusa tanto a vinculação pura e simples à esfera transcendental do eu puro (Husserl) quanto a dependência ao ser como destinação e envio do sentido, ao qual o humano deveria estar atento pelo pensamento meditativo (Heidegger), mas também, a férrea fixação às supostas características das meras coisas, vigente na "atitude natural".

\section{A antropologia filosófica de Fink: para além de Husserl e Heidegger}

Nos Fenômenos fundamentais opera, portanto, uma grande recusa: recusa da posição husserliana que pensa o elemento diferencial do humano a partir dos vividos intencionais da consciência; recusa da posição heideggeriana caracterizada por pensar o sentido de ser do ente que nós somos a partir do envio-destinação dos "clamores do ser"; recusa, também, de uma típica atitude, para retomar o ponto de partida deste texto, ligada, tanto ao que Husserl chamava de "orientação natural", quanto ao conhecimento manifesto nas ciências particulares. Estas creem que estão "[...] a caminho de entender o plano total das suas conexões internas" (Idem, p. 08), a partir do que elas dariam, então, uma resposta objetiva às perguntas. Tanto as ciências quanto a orientação natural operam com noções prévias inquestionadas. Elas, assim como as instituições, para funcionar, promovem, nas palavras de Fink, “[...] a redenção do suplício das perguntas" (Idem, p. 18). Ou, em outra passagem: "Todas as instituições já sabem demasiado sobre o homem - não há para elas mais nenhum enigma, nenhum labirinto no qual poderiam extraviar-se irremediavelmente" (Ibidem).

Por fim, também opera em Fink a recusa de uma antiquíssima e poderosa tradição, que se confunde com o próprio Ocidente, uma herança antiga e cristã, que consiste em

[...] determinar o "lugar do homem", por um lado, em ficar abaixo de Deus, e, por outro, em superar o animal, concebê-lo como um ser intermediário no qual se reúnem tensionalmente animalidade e divindade, a surda vitalidade animal e a chispa espiritual divina. (FINK, 1979, p. 266). 
Por essa razão, o autor manifesta que sua proposta de antropologia filosófica não se utiliza, nem de “[...] categorias zoológicas, nem teológicas na autocompreensão da existência humana". (Ibidem). Pode-se, portanto, chamá-la, como ele próprio o faz, de “[...] uma radical antropologia terrena” (Idem, p. 19).

Ao pensar a existência a partir da noção de fenômeno - posição expressa no título do seu curso: Fenômenos fundamentais da existência humana -, Fink põe fora de circulação a tradicional opção interpretativa que consiste em pensar a essência humana, mas também a atividade filosófica a partir da disjuntiva: ou transcendental, ou factual. Portanto, nem animal, tampouco divino; nem vida pura da consciência tampouco auscultação do ser no silêncio meditativo.

Como filosofia e existência se ligam neste pensamento? Diz-nos ele: "Filosofia é menos um saber douto que um modo de existir. [...] Ela nada mais é que a relação mais tensa da existência consigo mesma, e nisso consiste a fonte do seu compreender e do seu interpretar" (Idem, p. 35). Se existência é a abertura compreensiva, um estar aberto, "[...] ela vive no compreender" (Idem, p. 23), esta abertura se dá intensivamente enquanto relação diferencial, não apenas com o "[...] campo circundante" (Idem, p. 22) dos objetos e dos outros humanos, mas também, e principalmente, com a assunção do evento fundamental do pasmo constitutivo da própria atividade compreensiva: a existência aparece como um problema. No âmbito do mais conhecido emerge o estranhamento, por meio da compreensão de uma “[...] intimidade originária” (Idem, p. 24), constitutiva da existência. Neste âmbito de simbiose entre existência e filosofia, "[...] o mais importante é a comoção que nos acontece como destino - a comoção por um assombro abissal. Este assombro é a melhor parte do homem" (Idem, p. 10).

Com isso é possível constatar, como dito no início, que "cada teoria filosófica, mesmo quando a isso não se propõe, apresenta, a seu modo, uma definição particular, dada em nome próprio, do que é filosofia". A explicitação do significado de existência opera, ao mesmo tempo, uma explicitação compreensiva do que é filosofia, a saber: "pensar finito, uma possibilidade finita da existência finita". Portanto, compreensão da própria finitude. Dessa maneira, em Fink, finitude é o ponto de amarração de filosofia e existência.

Uma antropologia filosófica que pretenda compreender a existência em seus fenômenos fundamentais deverá mostrar, acima de tudo, boa consciência para com a finitude. Não à toa, um dos fenômenos fundamentais da existência humana é a morte. Se é inevitável reconhecer a morte como horizonte constitutivo, contudo, também constituem nossa existência os fenômenos da luta, do trabalho, do amor e do jogo. Como Drummond (1999, pp. 35-38) di- 
zia em seu poema Os últimos dias: "Que a terra há de comer. Mas não coma já. / Ainda se mova / para o ofício e a posse. [...] Uma parte de mim sofre, outra pede amor, / outra viaja, outra discute, uma última trabalha, / sou todas as comunicações, como posso ser triste?".

A antropologia filosófica de Eugen Fink constitui-se como um projeto filosófico que pensa o humano a partir destes cinco fenômenos fundamentais: morte, luta, trabalho, amor e jogo. Acompanhar sua argumentação, apresentada em sua obra Fenômenos fundamentais, exige um esforço de recusa e de deslocamento dos modos habituais de considerar o humano, herdados da tradição, seja filosófica, religiosa, científica, mas também de recusa das posições dos seus mestres, Husserl e Heidegger. O que se buscou foi simplesmente apresentar o esforço inscrito na tentativa de Fink de legitimar filosoficamente uma antropologia filosófica, sem entrar nos detalhes constitutivos da sua proposta, necessários para a compreensão da especificidade da sua antropologia filosófica. Embora esta seja uma tarefa preambular, nem por isso seu alcance é reduzido, pois ela serve de preparação para a compreensão, não apenas das recusas que operam no texto de Fink, mas também sobre aquilo que constitui a especificidade da sua antropologia filosófica.

Recebido em: 25.05.2018 | Aprovado em: 20.06.2018 $R$ Referência Bibliográfica

ARLT, Gerhard. Antropologia filosófica. Trad. Antonio Celiomar Pinto de Lima. Petrópolis, RJ: Vozes, 2008.

DRUMMOND DE ANDRADE, Carlos. Antologia poética. Rio de Janeiro: Record, 1999.

FINK, Eugen. Grundphänomene des menschlichen Daseins. (Hrsg. Von Egon Schütz und Franz-Anton Schwarz). Freiburg/München: Karl Alber Verlag, 1979. . Phänomenologische Werkstatt 2: Die Doktorarbeit und erste Assitenzjahre bei Husserl. (Hrgs. Ronald Bruzina). Freiburg/München: Verlag Karl Alber, 2008. - Phänomenologische Werkstatt 2: Die Bernauer Zeitmanuskripte, Cartesianische Meditationen und System der phänomenologischen Philoso- phie. (Hrgs. Ronald Bruzina). Freiburg/München: Verlag Karl Alber, 2006.

Proximité et distance. Essays et conferences phénoménologicques. Trad. Jean Kessler. Paris: Jerome Millon, 1994.

Welt und Endlickeit. Würzburg: Königshausen \& Neumann, 1990.

GIUBILATO, Giovanni Jan. Freiheit und Reduktion. Grudndzüge einer phänomenologischen Meontik bei Eugen Fink (1927-1946). Nordhausen: Verlag Traugott Bautz GmbH, 2017.

HEIDEGGER, Martin. Ser e Tempo. Trad. Fausto Castilho. Campinas, SP: Editora da Unicamp; Petrópolis, 
RJ: Editora Vozes, 2012.

"Sobre o humanismo. Carta a Jean Beaufret". In: Conferências e escritos filosóficos. Trad. Ernildo Stein. São Paulo: Abril Cultural, 1973. pp. 345-373.

HUSSERL, Edmund. A ideia da fenomenologia. Trad. Artur Morão. Lisboa: Edições 70, 1990.

Ideias para uma fenomenologia pura e uma filosofia fenomenológica. Trad. Márcio Suzuki. São Paulo: Ideias e Letras, 2006.

- Meditações cartesianas. Conferências de

Paris. Trad. Pedro M. S. Alves. Lisboa: Phainomenon e Centro de Filosofia da Universidade de Lisboa, 2010.

\section{"Phänomenologie und Anthropologie.}

Vortrag in den Kantgesellschaften von Frankfurt, Berlin und Halle". In: Aufsätze und Vorträge (19221937) - Husserliana XXVII. Pp. 164-181. Dordrecht/ Boston/London: Kluwer Academic Publisher, 1989. pp. 164-181.

Zur pPhänomenologischen Redukction.

Texte aus dem Nachlass (1926-1935) Husserliana XXXIV. Dordrecht/Boston/London: Kluwer Academic Publisher, 2002.

LÖWITH, Karl. Sämtliche Schriften 8. Heidegger Denker in dürftiger Zeit. Stuttgart: J. B. Metzler, 1984.

PATOCKA, Jan. Texte - Dokumente - Bibliographie. (Hrsg. Ludger Hagedorn und Hans Rainer Sepp). München/Freiburg: Karl Alber Verlag; Prag: Oikoymenh Verlag, 1999.

RICOEUR, Paul. Na escola da fenomenologia. Trad. Ephraim Ferreira Alves. Petrópolis, RJ: Vozes, 2009.

RUGGENINI, Mario. "Selbstbezug und Weltbezug. Grundprobleme der Anthropologie Eugen Finks". In: BÖHMER, Anselm (Hg.). Eugen Fink: Sozialphilosophie - Anthropologie - Kosmologie - Pädagogik
- Methodic. Würzburg: Königshausen \& Neumann, 2006. pp. 141-153.

SAN MARTÍN, Javier. "A fenomenologia de Husserl como antropologia: da oposição à exigência". In: Revista Páginas de Filosofia, v. 7, n. 1, p.27-41, jan.jun. 2015a. . Antropología filosófica I-De la antropología científica a la filosófica. Madrid: Universidad Nacional de Educación a Distancia, 2013.

.Antropología filosófica II - Vida humana, persona y cultura. Madrid: Universidad Nacional de Educación a Distancia, 2015b.

“Fenomenología transcendental y antropología filosófica”. In: MEDINA RENDÓN, Verónica (Org.). Antropología y fenomenología - Antropología filosófica y filosofia social. Ciudad de México: Centro mexicano de Investigaciones Fenomenológicas, 2017. pp. 63-82.

"Natur und Verfassung des Menschen. Zur Anthropologie Eugen Finks". In: BÖHMER, Anselm (Hg.). Eugen Fink: Sozialphilosophie - Anthropologie - Kosmologie - Pädagogik - Methodic. Würzburg: Königshausen \& Neumann, 2006. pp. 114-127.

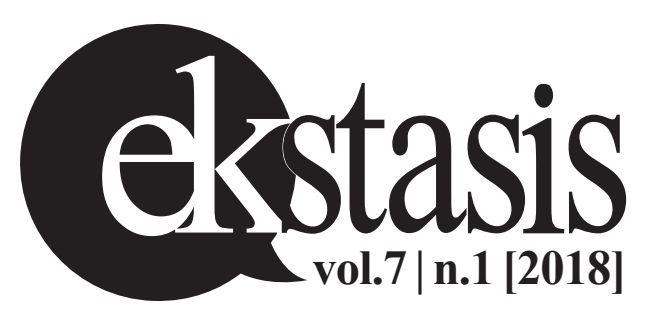

